This is an author-produced version of a peer-reviewed article. This version may not contain final publisher proof-corrections or pagination. The citation for the published article is:

Collier-Reed, B. I., Case, J. M., \& Stott, A. (2013). The influence of podcasting on student learning: a case study across two courses. European Journal of Engineering Education, 38(3), 329-339.

\title{
The influence of podcasting on student learning: A case study across two courses
}

\author{
Brandon I Collier-Reed ${ }^{\mathrm{a}}$, Jennifer M Case ${ }^{\mathrm{b}}$ and Angela Stott ${ }^{\mathrm{c}}$ \\ ${ }^{a, b}$ Centre for Research in Engineering Education (CREE), University of Cape Town, Cape \\ Town, South Africa \\ ${ }^{a}$ Department of Mechanical Engineering, University of Cape Town, Cape Town, South Africa \\ ${ }^{b, c}$ Department of Chemical Engineering, University of Cape Town, Cape Town, South Africa
}

\begin{abstract}
There is a growing literature on the educational benefits of using podcasting of lectures in higher education, but to date little research that interrogates closely its impact on student learning. The present study investigated how students used lecture podcasts when produced in two engineering courses at a South African university. The findings confirm much of the growing consensus in the literature. Firstly, a majority of students in the courses elected to use the podcasts. Secondly, the study notes that lecture attendance, in contexts where lectures are seen as beneficial, is not adversely affected. Thirdly, few students use podcasts in the mobile mode but most rather use them as an additional resource in their private study spaces. There is intense use in the build up to tests and examinations, and there is a particular benefit for students who are not first language speakers of the medium of instruction. This study also points to the existence of both deep and surface approaches to engaging with podcasts, with substantial evidence of many students using podcasts as a means towards better understanding.
\end{abstract}

\section{Key words}

Podcasting; Student Learning; Case Study; Engineering Education

\section{Introduction}

Podcasting, referring to the internet-based distribution of audio and/or video files, has attracted considerable attention over the last few years for its potential application to teaching and learning in higher education. As with all new technologies, there has been considerable hype and many overblown claims about its potential for revolutionising education and bringing about substantially changed learning outcomes. Nonetheless, there has also been a steadily increasing group of lecturers who have been using podcasting towards a range of ends in their courses, and there is now an established literature that reports on this work. Hew (2009) notes the largest proportion of these reports come from the disciplinary areas of engineering and science, as might be expected, given the role of technology in these disciplines and the likely backgrounds and skills of these lecturers.

A recent review of podcasting in higher education (McGarr, 2009) identifies the following key question: "How will podcasting influence the traditional lecture in higher education?" This resonates with a recent article in this journal which posed a similar question: "Is attending lectures still relevant in engineering education?". Fitzpatrick and colleagues (Fitzpatrick, Cronin, \& Byrne, 2011) at University College in Cork, Republic of Ireland, surveyed their undergraduate chemical engineering students to explore this question. Their study concludes that, for the overwhelming majority of students, "lectures are still 
beneficial to their learning and are not an out-of-date mode of education even in the modern era of information and communication technologies" (p. 311).

The central issue is therefore not the technology. It is student learning. In what ways does the use of podcasting have the potential to impact positively on student learning? Much of the current research has been in disciplinary areas such as medicine and law. Scutter et al. (2010), for example, has noted the value of podcasts in what he terms 'content heavy' disciplinary areas. The engineering curriculum has its own distinct knowledge structure and associated student learning challenges, and thus there is value in carefully exploring this question in context. In this article we therefore wish to foreground an educational interrogation of the potential value of using podcasts of lectures in engineering education. We focus on how students make use of podcasts with the objective of understanding how this practice impacts on student learning.

\section{Podcasting in higher education}

The technologies available in the podcasting arena are developing rapidly. It is interesting to note that a review of the field published recently (Hew, 2009) focuses exclusively on audio podcasts. In this article Hew notes the inherent limitations of podcasts of this nature and points promisingly to the possibility of the 'vodcast'. Only a few years later, the synchronous production of audio and visual material, shown empirically to be superior to asynchronous slides and audio (Griffin, Mitchell, \& Thompson, 2009), is now easily accomplished, and indeed is the focus for the present study.

A few recent reviews (Heilesen, 2010; Hew, 2009; McGarr, 2009) provide a useful mapping of the terrain and offer some tentative syntheses of what has already been learnt.

Heilesen (2010) suggests that many of the reasons why an institution might embrace podcasting and other such application of ICTs to education are not necessarily educational in nature. Rather, they include a wish to modernize, to be competitive and to respond to growing student demand for particular kinds of services. McGarr (2009) notes that the earliest studies of podcasting tended to be surveys on user preferences with regard to the technology itself, and that initially there were very few studies that focused on educational issues. This situation is now changing and there are an increasing number of scholars addressing podcasting in higher education from a teaching and learning perspective. The present study attempts to make a contribution to this literature.

McGarr, citing Higgins (2003), notes that educational innovations are often adopted by teachers without proper account being taken of their potential educational implications. Laurillard (2008) notes that being 'technology-led' rather than driven by real educational considerations, is always likely to lead to less than optimal solutions. With regard to podcasting, she notes quite critically that iPods were developed as a technological solution for listening to music, not necessarily for learning. We should not assume that the adoption of a fancy new technology will necessarily bring anything more meaningful than fun and hype in its wake.

The range of possible applications of podcasting in higher education have been classified in various taxonomies. Important distinctions are whether they are lecturer-created or student-created, and whether they simply capture the lecture or offer supplementary material (cf. Hew, 2009). Our focus in this article is on the application of podcasting for producing audio and video records of the lecture itself that students might download and watch at different times and in different places, what Hew (2009) terms the 'lecture podcast'.

Heileson (2010) makes the pertinent observation that the use of audio-visual teaching materials is hardly novel; most probably established now for about a century. What is however new with podcasting technology is the extraordinary ease with which materials can 
be created and distributed (Hew, 2009). Being able to review these resources has also become a mainstream reality with limited requirements for new equipment or hardware as smartphones, laptops and internet access are now well distributed across the developed world. Furthermore, the increasing availability of affordable smartphone technology has made the developing world also able to access streaming video content cost effectively.

Methodologies for researching students' use of podcasts have been helpfully categorised by Heileson (2010) as 1) questionnaires, focus groups and individual interviews in a course context; 2) measuring student access to podcasts or measuring student performance in a course context; and 3) controlled experiments. There have also been a small number of surveys across whole departments or institutions, where students would have experienced the use of podcasts in different courses. A number of key findings are starting to emerge from this literature.

Firstly, a common concern voiced by lecturers is that lecture attendance will substantially drop if podcasting is introduced in a course. Maybe surprisingly, in a large number of studies across a wide range of contexts, there is little evidence that this is the case (Heilesen, 2010; Hew, 2009; Lonn \& Teasley, 2009; McGarr, 2009). Hew (2009) suggests that in fact this is not surprising, as students still value the opportunities to interact and to ask questions that are provided by face-to-face lectures. McGarr also comments on studies that show that students tend to use podcasts for revision rather than as a replacement for the lecture.

Secondly, a stated aim for podcasting was the vision of mobile learning ('m-learning') where students could listen to podcasts while doing other things, for example while doing housework or taking public transport. The studies that have investigated where and when students choose to listen to podcasts have generally found that, while a small minority do indeed undertake this mode of learning, the vast majority choose to use podcasts in the same kind of environment where they generally undertake their studying; watching the podcast on a PC or a laptop, rather than on an MP4 player or other similar device (Heilesen, 2010; Hew, 2009; McGarr, 2009).

There is much evidence that students are using podcasts in preparation for tests and examinations (Heilesen, 2010). Lonn and Teasley (2009) in a survey across a whole institution where podcasting had been adopted in many courses, found that students in general only downloaded podcast material a few times in the semester, in preparation for assessment events. A similar institution-wide study by Fietze (2009) in Germany found a similar situation. Crucially, students now have flexibility in time and space as to when they choose to use the lecture material.

Regarding the potential impact of podcasting on student performance, this is always going to be difficult to determine. There are so many aspects of the learning context that influence student performance and control/experimental designs are notoriously difficult to carry out in real educational contexts given the difficulty of creating sufficiently large and matched groups of participants, never mind the practical and ethical complexities of offering only part of a class access to an educational innovation. Heilesen (2010) concludes that the evidence for a beneficial impact of podcasting on student learning outcomes is 'slim', thus tending to concur with the conclusion of Hew's (2009) earlier review. Positive impacts that have been noted might well be related to an increase of more fundamental learning activities such as actively engaging and revising (see, also, Lonn \& Teasley, 2009; McGarr, 2009). In other words, the introduction of podcasting in these courses might have simply assisted students in exercising better study habits. On the other hand, we should not dismiss out of hand an innovation that has been able to facilitate an improvement in the underlying quality of student learning! 


\section{The research site and the technology employed}

This study draws on two undergraduate engineering courses in the Faculty of Engineering and the Built Environment at the University of Cape Town in South Africa, one located in the Department of Chemical Engineering and the other in the Department of Mechanical Engineering.

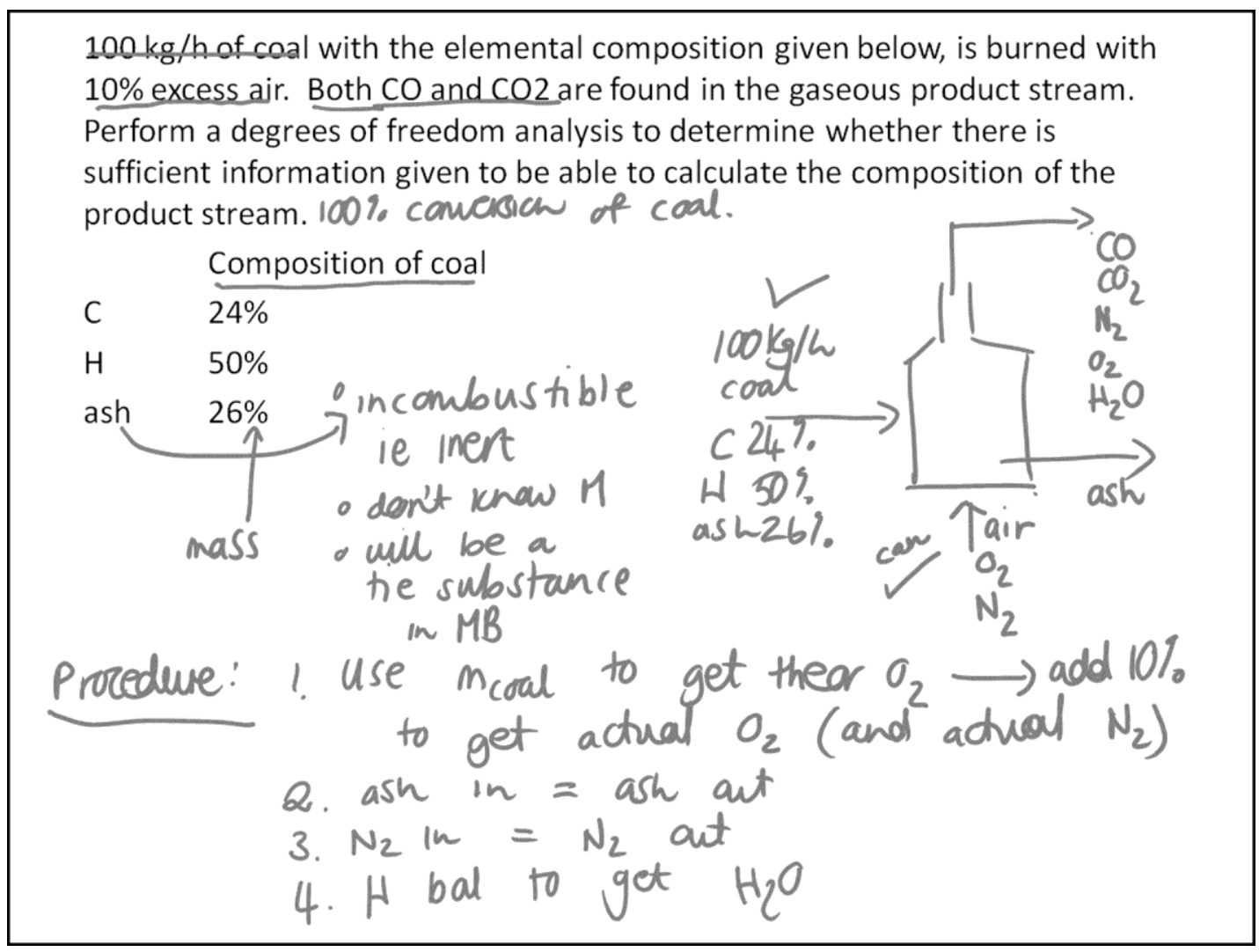

Figure 1: Example of a slide recorded during the material and energy balances course showing the analysis undertaken and calculations performed.

The chemical engineering course is a second year course in material and energy balances typically taught to in the order of 120 students and consists of 60 lectures spread over a 12week period. During this course, students focus on material balances both with and without reaction and cover topics such as chemical equilibrium, heat and work - as well as the simultaneous balancing of both material and energy equations. This is a core theoretical course in the degree programme where students are required to grasp the basic analytical tools of the discipline. Focus is directed toward understanding the basic concepts involved in material and energy balances as well as being able to calculate the outcomes of these reactions. The course has formal lectures as well as dedicated tutorial sessions where students have the opportunity to grapple with the calculations that arise from the material covered in the course. The course has been the subject of much educational innovation over the years in an attempt to improve student learning (see, for example, Case, Gunstone, \& Lewis, 2001). However, concerns remained around how to facilitate consistent student engagement through the semester, especially of the students performing at the lower end of the class. In moving to the use of podcasting in this course, a key requirement was to be able to replace the traditional use of a blackboard for the presentation of the material covered (calculations, derivations, etc) by a digital representation of this blackboard space that could then be 
recorded. Figure 1 illustrates an example of the type of analysis undertaken and calculations performed in the class as captured in a podcast.

The mechanical engineering course is a second year course focussing on manufacturing processes and typically has in the order of 160 students enrolled. The course consists of 12 lectures spread over a six-week period and covers processes related to the forming, shaping, wasting, joining and finishing of materials and components. As such, it is a richly descriptive course that lends itself to the use of multimedia-rich presentations something that had not been implemented in prior years. The course is lecture-based with no formally scheduled tutorial sessions, although time was set aside during specific lecture periods to address issues arising from worksheets provided to students. The class itself was relatively large with many students struggling during the assessment of the work covered given its descriptive nature. Once again, consistent student engagement with the material was considered as essential to the success of students. Adopting a podcasting-friendly approach to the presentation of material was enabled through the use of PowerPoint as this meant that the process-related videos, imbedded animations and illustrations that made up most of the content of the course could be captured and made available in toto for students.

While a PC-based tablet was specifically described above as being utilised in the chemical engineering course and PowerPoint in the mechanical engineering course, a mixedmode application of ICTs was implemented across both courses; both made use of PC-based tablets for the traditional 'blackboard teaching' and PowerPoint for presentations as required. Both audio and video was recorded for the podcasts in these two courses, and complete virtual lectures were created from the PowerPoint- and tablet-based interaction with the respective classes. Furthermore, in both courses, where appropriate, the solutions to past tutorials and assessments were also recorded as podcasts - albeit at times recorded outside of the classroom and thus more supplemental in nature (see McGarr, 2009) than the other podcasts recorded as part of formal contact time. Camtasia Studio (techsmith.com) was used to capture what was taking place during these lectures and supplemental presentations. The recordings were made available to students through the university's virtual learning environment (VLE) based on the Sakai platform (sakaiproject.org).

The technical implementation of the requirements necessary to produce the podcasts required no custom solutions but rather utilized readily available off-the-shelf components including a touchscreen tablet-style notebook for presentation, a stylus to make the relevant markup on the slides themselves, and a cordless lapel microphone to integrate voice into the video recording. In the case of the material and energy balance course, the integrated notebook microphone was used.

\section{Data collection and analysis}

This is a case study on the use of podcasts in two second year university courses taught by the first two authors. The study does not attempt to allow for grand generalisations (Stake, 1994). Instead, its value is in allowing readers to form fuzzy generalisations (Bassey, 1999), or working hypotheses (Merriam, 2009) about how these cases may improve understanding of other cases. Consistent with this, we provide as many direct quotes from students as space allows, enabling readers to assess the transferability of these insights to their context (Lincoln \& Guba, 1985).

The two cases deliberately draw on a range of different modes of data collection in order to as widely as possible explore this new context. A number of course-based surveys assisted in the collection of these data. In the mass and energy balance course, four surveys were administered - one after each assessment event. With a class size of 121 , there were 97 , 106,67 , and 79 responses to each of these surveys. These surveys asked students to indicate 
their use of several of the resources made in the course including old tests and exams, the textbook, the tutor, lecturer, podcasts, and PowerPoint slides from the lecture. For each of these resources, students were asked how the resource was used or alternatively, why a particular resource was not used. In the manufacturing processes course, students completed a resources survey at the beginning of the course and towards the end of the course a survey on podcasting in the course specifically. Both questionnaires contained open- and close-ended questions and from a class of 161 students, there were 141 and 131 responses to these surveys respectively. The first survey focussed on students access to devices to watch or listen to podcasts as well as whether they had recorded any part of a lecture before. It also inquired as to whether they felt there was any value to making recorded lectures available and whether this may result in fewer lectures being attended. The second survey asked whether students had watched or listened to any of the lecture recordings to date (or planned to do so in the future), and interrogated their record of lecture attendance during the course. It also asked what they felt had been the greatest benefit of having recorded lectures available and what could have been done to make the recordings more useful as part of the educational process.

These survey-based data were complemented by in-depth interviews with a purposive sample of students at the conclusion of each course. In both courses, students with varying academic abilities - as evidenced by their academic results to date - were invited to participate in a series of focus group interview sessions. In the chemical engineering course a total of 23 students were interviewed in four focus-group sessions, while in the mechanical engineering course, 13 students contributed to three focus-group interview sessions and there were additionally three individual interviews. One of the mechanical engineering students participated in both a focus-group as well as an individual interview for a total of 15 students providing data for this course.

As an additional source of data, supplementary information was captured in lecturer journals and spontaneous communications with students. Finally, students were required to retrieve the podcasts from the University's VLE which logged all activity related to each course. From this database, it was possible to retrieve all data relating to the downloading of these recordings.

In all cases, the data were collected after clearance had been granted by the Faculty's Ethics in Research committee and access to the students had been authorised by the University. Survey data were all anonymously collected and students who consented to being interviewed were given the assurance that their identities would remain anonymous. In the case of the manufacturing processes course, the interviews were undertaken prior to the students having completed the course. To ensure the trustworthiness of these data, a person not involved with the course (the third author) interviewed the students. These data were not accessible to the lecturer until after the completion of the course. To ensure consistency of the interview data, the same person interviewed students from both of the courses.

Most of the data collected were qualitative. This is appropriate, since the purpose of this research was to gain an in-depth understanding of the case (Merriam, 2009). Data analysis was undertaken through an inductive, iterative process which was grounded in the data (Glaser \& Strauss, 1967). It was directed by the research question: "How do university students use podcasts in their learning". Through a process of coding and constant comparison of the data, categories emerged that that accounted for the data under analysis. 


\section{Findings}

\subsection{Electing to make use of podcasts}

From the outset it was made clear in both courses that the lectures were being recorded, and access to the recordings was demonstrated and encouraged. As revealed by a survey conducted at the beginning of the manufacturing processes course, almost all the students had access to devices capable of playing these recordings (see Figure 2). Additional data collected in this course revealed that a number of students have a desktop, but not laptop, computer, improving the relative number of students who have immediate access to their own computer to $94 \%$ of the students who responded. Only one student indicated having no access to any of the devices listed. These findings are supported by the 2012 Educause Centre for Applied Research student technology survey (educause.edu) of 746 undergraduate students at this institution, representative of race and gender, and spread by year of study, which showed laptop ownership at $94 \%$.

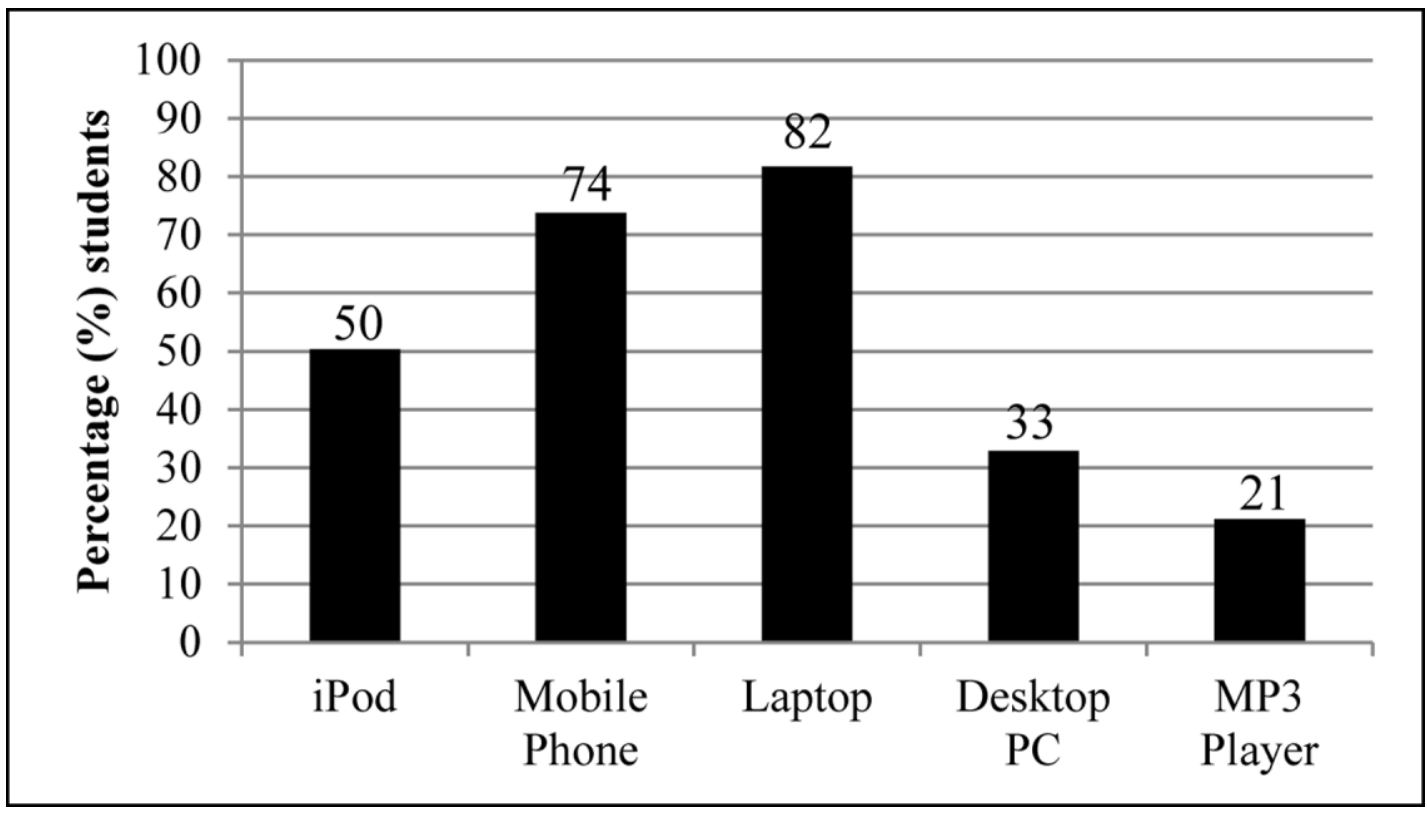

Figure 2: Distribution of devices able to play audio (mp3) files in the manufacturing processes course.

The survey data collected during the course showed that while the majority of students made use of the podcasts to support their learning, there were some who did not. There appear to be two primary reasons for not using the podcasts: Lack of access to the resources in their chosen place of study and a lack of perceived need of podcast usage for learning success. A lack of convenient access is illustrated by the following quotes: 'I didn't have a laptop in my room - the problem is me having to go to the labs and stuff - so that is the main reason [I didn't make use of the podcasts]' and 'I did sometimes go to the labs and listen to what I needed to listen to - but other times it is just too much of an effort - you pretend you know what is going on'. Students who reported a lack of perceived need of podcast use for learning success found the more traditional resources available in the courses sufficient: 'I have my notes - I didn't feel that I had to listen to the whole lecture again'; 'Personally I don't use podcasts at all. I need to work through an example that is explained for me to understand'; and finally 'I never used the podcast - I used the PowerPoint [slides] once or twice. I found 
the text book extremely helpful'.

In some cases this resistance to podcast usage was temporary, as suggested by the change in the students' reported podcast usage across the duration of the material and energy balance course, as shown in Table 1 . Near the start of the course, $61 \%$ of the students reported podcast usage and $18 \%$ indicated that they did not make use of them because they had 'no need' to do so. The initial high reported usage may have been due to excitement about a new resource. Some of this appears to have waned by the following survey, which coincided with the first assessment event, since a reduced proportion $(54 \%)$ reported podcast usage. Additionally, a greatly increased proportion (26\%) indicated a lack of perceived need for podcast usage. However, by the final survey, conducted near to the final assessment event, it appears that students' views on podcast usefulness had improved even beyond the initial level, since $65 \%$ reported using podcasts, and only $10 \%$ indicated a lack of perceived need for podcast usage.

Table 1: Outcome of the four surveys administered during the material and energy balance course regarding the use of podcasts and other resources in the course.

\begin{tabular}{|l|c|c|c|c|}
\cline { 2 - 5 } \multicolumn{1}{c|}{} & Survey 1 & Survey 2 & Survey 3 & Survey 4 \\
\hline Podcasts used & $61 \%$ & $54 \%$ & $55 \%$ & $65 \%$ \\
\hline No time available & $2 \%$ & $4 \%$ & $1 \%$ & $3 \%$ \\
\hline No need to use them & $18 \%$ & $26 \%$ & $16 \%$ & $10 \%$ \\
\hline $\begin{array}{l}\text { Other reason given for } \\
\text { not using podcasts }\end{array}$ & $19 \%$ & $16 \%$ & $28 \%$ & $22 \%$ \\
\hline
\end{tabular}

The use of podcasts as a substitute for lectures is a potential concern. While this does occur, the data suggest this is not prominent. Students reaffirmed the value of live lectures, such as the enhanced interaction they provide relative to the podcasts. For example, one student commented, 'if you are watching a movie or a live play I feel that the interaction with the live play is better than just watching a movie' and that 'the main thing is you lose [by just watching the podcast is] immediate interaction'. In a survey completed by $81 \%$ of students registered for the manufacturing processes course, $35 \%$ reported not attending all the lectures. However, only $10 \%$ suggested that this was due to the podcast availability. Common to all courses, students missed lectures during these courses for both academic and personal reasons. For example, one student said, 'sometimes you don't miss a lecture intentionally maybe something happens and you can't go. Then the podcasts can be [a] good backup there. Which is better than copying someone's notes and they don't know why they are writing'. The majority of lecture absences were reported as being due to the student having to balance academic demands on their time, such as assignment submissions or assessment events: 'I wouldn't have gone - because I could watch it [the podcast] in the evening after my test'. The overwhelming response to the provision of podcasts was that they provided a safety net that enabled students to 'recover' from not being able to attend a lecture.

\subsection{Considering time and place}

The students reported a variety of approaches to podcast usage. Some students watched the podcasts regularly: 'I used it almost every day - I'd rather listen to [a] podcast than look at the text book. I'd take like thirty minutes to listen to the podcast ...'. Others found this frequent viewing less important as the course went on: 'Initially I was using them every day 
but sometimes you feel confident you saw it live in the class and you understand almost everything - for me it wasn't enough reason to go over them again'.

It was most common for students to make use of their weekends to review the material as 'it is only two lectures per week [for the manufacturing processes course] probably less than two hours of lectures so during the weekend you can actually recap and get everything done in a sense'. The excerpt below illustrates how a student strategically reviews a podcast during the week followed by a more thorough engagement with the material on the weekend:

\footnotetext{
' $\ldots$ at first I would just watch it which is about 30min long - from there I would jump into pieces that I didn't get; writing down for a visual guide to get understanding of those concepts which would be on a Saturday - not only on a Saturday because I was doing it again during the week. Like Saturday was the day I did it really properly.'
}

There were a total of 2270 podcast downloads during the manufacturing processes course. An interrogation of the data available from the course's VLE suggests that a core group of students made use of the recordings on an on-going basis, and another group focussed on using the podcasts to aid their preparation for an assessment event. The course was offered during the second of four academic quarters. This was followed by a three week university examination period (where the course was not examined), a six week mid-year vacation, and the class test for the course was scheduled for the beginning of the third week of the third quarter. It is interesting to note from the data that there is a spike in download activity to 158 downloads that occurs at the end of the academic term before the three week examination period. During the examination period there was a steady increase in the number of downloads taking place and by the end of the examination period, a total of 331 downloads had occurred during the period. In the two weeks before the formal class assessment for the course, $46 \%$ of the total downloads for the course took place by $84 \%$ of the class.

Only a limited number of students reported that they used the podcasts outside their quiet places of study. In these instances, the lecture's audio file was listened to from a multimedia device, while another activity, such as a bus ride, was engaged in: 'I like to listen to the audio on the shuttles ... probably I am coming to a lecture or coming to the library after hours, I'll put it [the audio of the lecture] on my phone.'

\subsection{Considering the impact on learning}

There is evidence that some students simply rewatched the full podcasts, hoping to 'absorb' the work: 'That is pretty much how I used them - I just sat replayed them to myself until I felt that I had withdrawn all the relevant information from the actual flash files'. For these students, simple repeat viewings of the podcast formed an important part of their use of the material in the course. However, for the majority, podcasts were used primarily as an aid to understanding the material presented in class, as evidenced by remarks such as, 'I'm not content with just understanding a surface definition - I like to go into more depth and [podcasts] allowed me'. This view was often associated with the difficulty of following what was happening in the classroom, and the convenience and safety of being able to rewatch the lecture in podcast form at the student's own pace, in their personalised learning space, using the pause and rewind functions. This appeared to be particularly so for students whose home language is not English, such as for the student below: 
'Sometimes the lecturer is talking to 100 students and you feel left out but when you listen to the podcast it is literally like a one to one situation with the lecturer as well which is better. For some of us the command of English isn't that [good] so the problem of hearing each and every word and understanding each and every word the first time it is actually said in that sentence it is not so easy for us as well. So you can rewind the [podcast] if you didn't understand.'

Students often distinguished between the ease of understanding the material covered in the classroom versus in a quiet place of study. The students tended to characterise the classroom as a space saturated with content, discussion, and, sometimes, distraction, whereas the podcast's greater simplicity helped them focus on understanding the concepts taught. Students broadly suggested that 'the podcast helps you to understand the concept to enable you to apply it in order for you to get a better understanding of the concept'. The podcasts were often used to revisit the material covered in class to enhance awareness of the nuances of the lecturer's argument and so aid the student to develop a clearer understanding of the work:

'I went to every lecture but sometimes I would miss small details and those small details would sometimes help me understand the work better and was the most valuable thing from the podcast - the small details, the subtleties in the understanding that I gained from it.'

Some students reported that occasionally they only became aware of their lack of understanding after a lecture, for example while reading their notes or the textbook. As illustrated by the excerpt, this realisation of a lack of understanding sometimes motivated podcast usage:

'... you think you understand sometimes and when - let's say [the lecturer] speaks and [my friend] writes down - later when I look at what we are doing - so in class I think I understand - I should go back and listen to what she is saying but I say "no", I do understand and then only later - I didn't quite understand the concept ...'

\subsection{A change of approach to engaging in class}

Many students remarked that it is not particularly useful to write verbatim notes of the lecturer's words during a lecture. The quotation below is representative of this view. The student is referring to lectures for courses for which podcasts are not available:

'A lot of the time I'll write something down and sometimes I am just writing because I need to get it down and then I'll look back at it later and think - it doesn't make sense. I was writing down the concept by parroting what the lecturer was saying but you know by parroting just because you've written down exactly what he says doesn't mean that you actually understand the concept.'

For a number of students, this realisation prompted a change in their approach to classroom engagement since having access to podcasts allowed them to concentrate more fully on the lecturer's argument rather than frantically having to capture notes:

'When I went to lectures - especially like maths you spend so much time trying to scribble down all the notes that you can and then you miss understanding all the concepts. I'd sit in lectures and try to understand what was going on - when I go home I 
play the podcast and that is how I would do my notes - when I am watching the podcast at home.'

\section{Discussion and Conclusion}

The modest applications of podcasting in the two courses that made up this case study simple technology, synchronous recording of the lecture as it took place, minimal postproduction - has been shown to have potentially significant impacts for student learning. In both these engineering courses podcasting was extremely well received by students, and an interrogation of their modes of engagement with this resource suggest that in most instances it impacted positively on the quality of their learning.

While a substantial literature has already developed relating to the potential educational benefit of podcasting to education, although largely not in engineering contexts, in this study we sought to find out whether some of the reported benefits and limitations would also hold in our context. At a basic level, we have presented here further confirmation of some of the key findings in the literature to date. Contrary to assumptions, students' patterns of lecture attendance do not appear to be strongly affected by podcasting of the lectures. It is very likely that this only holds though for lecture contexts where students already see benefits of attendance and where lecture attendance already is relatively high. It needs to be noted here that as a South African residential university we have students who are not typically taking on part-time employment alongside their studies. We also attract highachieving school leavers who are often industrially funded, and it is thus likely that we have a fairly high level of commitment to lecture participation as a baseline.

A further key finding from the literature that we corroborate here is that students do not tend to use podcasts in the 'm-learning' mode i.e. on buses, during waiting time, at gym, etc. The students in this study largely reported using the podcasts in their private study spaces. The podcast was an additional resource in a space where they already worked with lecture notes, tutorial assignments and textbooks. We can also confirm that the use of podcasts did increase as tests and examinations approached - this really only confirms what we already know about student study behaviour, which is that it is largely directed towards assessment events. We also have some evidence that the podcast offered particular benefits for students who are not first language speakers of English, the medium of instruction at this university.

What this study offers that is not previously much reported in the literature is a closeup look at student learning in the context of podcasting in engineering education. In our results we find something akin to the deep-surface distinction between student approaches to learning. While we find limited evidence in the data of students making use of podcasts at the surface end, we have extensive evidence of students who are using podcasting to support deep approaches to learning. These are students who sought out particular parts of the podcast to deal with concepts that they had not yet grasped. Here we note an active and directed mode of engagement with the podcast. At the high end of quality student learning, we note a small group of students who are using the podcast to allow for a completely different way of engaging with the lecture: being able to be much more selective about how much attention they direct to note-taking, and how much they are able to use for active engagement. This latter finding is significant and points to an area where further development could allow for a significant impact on student learning. 


\section{References}

Bassey, M. (1999). Case study research in educational settings. Buckingham: Open University Press.

Case, J., Gunstone, R., \& Lewis, A. (2001). Students' metacognitive development in an innovative second year chemical engineering course. Research in Science Education, 31(3), 313-335.

Fietze, S. (2009). Podcast in higher education: Students usage behaviour. Same places, different spaces. Proceedings ascilite Auckland 2009, 314-318.

Fitzpatrick, J., Cronin, K., \& Byrne, E. (2011). Is attending lectures still relevant in engineering education? European Journal of Engineering Education, 36(3), 301-312.

Glaser, B. G., \& Strauss, A. L. (1967). The discovery of grounded theory: Strategies for qualitative research. Chicago,: Aldine Pub. Co.

Griffin, D. K., Mitchell, D., \& Thompson, S. J. (2009). Podcasting by synchronising PowerPoint and voice: What are the pedagogical benefits? Computers \& Education, 53(2), 532-539.

Heilesen, S. B. (2010). What is the academic efficacy of podcasting? Computers \& Education, 55(3), 1063-1068.

Hew, K. F. (2009). Use of audio podcast in K-12 and higher education: a review of research topics and methodologies. Educational Technology Research and Development, 57(3), 333-357.

Higgins, A. (2003). On learning and teaching with technology: Principles and practices. In S. Naidu (Ed.), Learning and teaching with technology (pp. 289-291). London: Kogan Page.

Laurillard, D. (2008). The teacher as action researcher: using technology to capture pedagogic form. Studies in Higher Education, 33(2), 139-154.

Lincoln, Y., \& Guba, E. (1985). Naturalistic inquiry: Sage Publications.

Lonn, S., \& Teasley, S. D. (2009). Podcasting in higher education: What are the implications for teaching and learning? The Internet and Higher Education, 12, 88-92.

McGarr, O. (2009). A review of podcasting in higher education: Its influence on the traditional lecture. Australasian Journal of Educational Technology, 25(3), 309-321.

Merriam, S. B. (2009). Qualitative research : A guide to Design and Implementation. San Fransisco: Jossey-Bass.

Scutter, S., Stupans, I., Sawyer, T., \& King, S. (2010). How do students use podcasts to support learning? Australasian Journal of Educational Technology, 26(2), 180-191.

Stake, R. E. (1994). Case studies. In N. K. Denzin \& Y. S. Lincoln (Eds.), Handbook of qualitative research (pp. 236-247). Thousand Oaks: SAGE. 